\title{
SCHOLARSHIP IN MEDICAL EDUCATION
}

Yvonne Steinert

Ph.D. in Clinical Psychology. Director of the Centre for Medical Education, McGill University. Montreal, Québec, Canada. yvonne.steinert@mcgill.ca

The publication of a new journal on medical education in Brazil celebrates a pivotal moment in the growth and development of medical education in this country. It also marks the importance of scholarship in medical education and provides an important venue for the dissemination of scholarly work that will help to ensure the use and uptake of "best evidence" in teaching and learning as well as educational design, delivery and evaluation.

Although scholarship is a term that has been increasingly used in health professions education globally, it is not easy to find an equivalent word in Portuguese. This editorial will focus on the meaning of scholarship, why it is important, and how we can try to maximize opportunities for scholarship in our daily work.

In 1990, Boyer identified four categories of scholarship: discovery; integration; application; and teaching'. The scholarship of discovery has been synonymous with research in the traditional sense. In medical education, this can include original research (e.g., how clinical reasoning develops over time) or forming new theory (e.g., why physicians teach). Peer-reviewed grants and publications are often products of the scholarship of discovery ${ }^{2}$. The scholarship of integration has been defined as making connections across the disciplines, illuminating data in a revealing way. Examples in medical education include knowledge syntheses (e.g., systematic or scoping reviews) or integrating concepts from other fields such as anthropology, sociology or education into medicine. The scholarship of application has been likened to "service" in one's own field of knowledge, to the application of theory into practice. A common example is using research evidence to develop a new curriculum or assessment method based on available evidence. In medical education, designing innovative instructional materials or developing a faculty development program are examples of the scholarship of integration and application $^{3}$.

The scholarship of teaching entails two components. It refers to the application of scholarly activities to teaching - that is, a going "meta", a "process by which teachers frame and systematically investigate questions related to student or resident learning" 4 It also requires effective dissemination of the results. As Glassick ${ }^{5}$ noted, "teaching becomes scholarship when it is made public, is available for peer review and critique, and can be reproduced and built upon by other scholars" 5 . Importantly, the scholarship of teaching is not synonymous with excellent teaching; rather, it includes the description and dissemination of effective and novel teaching methods and strategies, in a research presentation or publication like this Journal.

As clinicians and educators, we frequently fulfill multiple educational roles (e.g., teacher, assessor, course developer), and we have a responsibility to provide excellent education with inadequate time to devote to the task. Given this reality, why is scholarship important? The reasons vary. On the one hand, education is a core mission of an academic institution, despite the perception that research or clinical service may often appear to take priority. 
Scholarship promotes and validates medical education as an academic activity; it also moves the field forward. In addition, improved educational scholarship offers benefits to teachers, learners and the institution. For teachers, this includes more effective teaching and curriculum design, personal recognition and academic advancement, and increased satisfaction. The dissemination of educational innovations also ensures the sharing of successful teaching and assessment methods and the use of "best evidence" in the classroom and the clinical setting. For learners, the results of educational scholarship may include enhanced learning and satisfaction. Scholarship also has the potential to influence career choice; scholarly teaching may motivate learners to choose the teacher's area of expertise or, alternatively, a career in medical education. For institutions, educational scholarship may lead to better curricula, a broader research agenda, and increased recognition and status - for education and for the institution at large ${ }^{3}$.

Given competing needs and priorities, how can we maximize opportunities for scholarship? As a start, we should always think about which of our many tasks might lead to scholarship. For example, we can reflect on the activities in which we are involved, whether as a teacher, assessor, or course developer, and ask ourselves what has the potential to progress to scholarship. There are many opportunities for scholarship in our daily work; we should start with one. It is also helpful to work together with a team of colleagues. Whenever possible, we should think about evaluating our educational programs and activities and conducting research on areas that are relevant to our context and to our passions. We should also collaborate with peers and students so that we can effectively implement and evaluate new ideas, and in the process, demonstrate the link between scholarship and educational practice.

In closing, scholarship in education involves the discovery of new knowledge, the integration or application of existing knowledge to new areas, or a scholarly approach to teaching with effective dissemination of outcomes of innovation ${ }^{6}$. The creation of this new Journal helps to accomplish this critically important objective.

\section{REFERENCES}

1. Boyer EL. Scholarship Reconsidered: Priorities of the Professoriate. San Francisco, CA: Jossey-Bass; 1990.

2. McGaghie WC. Scholarship, publication and career advancement in health professions education: AMEE Guide No. 43. Med Teach. 2009;31 (7):574-590.

3. Steinert $Y$, Snell L. Educational innovation and scholarship: from curriculum design to implementation. In Sherbino J, Frank RJ, editors. Educational Design: A CanMEDS Guide for the Health Professions. Ottawa: Royal College of Physicians and Surgeons of Canada; 2011 ; p. 87-92.
4. Hutchings $P$, Shulman LS. The scholarship of teaching: New elaborations, new developments. Change 1990;31(5):11-15. doi: $10.1080 / 00091389909604218$

5. Glassick CE. Boyer's expanded definitions of scholarship, the standards for assessing scholarship and the elusiveness of the scholarship of teaching. Acad Med. 2000;75(9):877-80.

6. Simpson DE, Fincher RM. Making a case for the teaching scholar. Acad Med. 1999;74(12):1296-9. 